\title{
Theoretical Approaches to Study SMEs eBusiness Progression
}

\author{
Fernando Alonso Mendo and Guy Fitzgerald \\ Department of Information Systems \& Computing, Brunel University, Uxbridge, UK
}

It has been suggested that the adoption of Internet technologies by SMEs follows an ordered sequence of stages and staged models to describe it. These models postulate that businesses move in stages from basic use of the Internet to the full integration of business systems and redesign of business processes. The European Union and the UK government appear to believe in such models and have used them in their e-business adoption encouragement policies for SMEs. However, despite the efforts of governments and the various support programs, the attainment of the advanced stages of e-commerce by SMEs is very low. Indeed, several studies into the state of e-business in the UK report a decline in the number of SMEs implementing e-trading and even using website and e-mail. Hence, perhaps these adoption models need to be questioned and even revised. There are a number of authors that have already critized these models suggesting that they are too general and do not take into account the diversity of SMEs. Therefore, the aim of this paper is to conduct an analysis of the Stages of Growth model looking at its weaknesses and strengths in the context of the progression of Internet technologies adoption by SMEs in the UK. In addition, alternative explanations of e-business progression will be presented and an interpretative multi-theoretical framework to study this evolution will be suggested.

Keywords: SMEs, e-business, e-commerce, Internet adoption, Stages of Growth model, theories of change.

\section{Introduction}

Small and medium-sized enterprises (SMEs) make up a very heterogeneous group. The realm of SMEs encompasses organisations with less than 250 employees, a turnover lower than 50 million $€$, and which are owned for less than $25 \%$ by non-SMEs, except banks or venture capital companies [28]. SMEs comprise the vast majority of enterprises in the UK Economy and employ a significant sector of the workforce.
At the start of 2002, the percentage of the workforce employed by SMEs was 55.6\%, the percentage of firms that were classified as SMEs was $99.8 \%$, and these firms accounted for $52 \%$ of the business turnover [72].

One of the main characteristics of SMEs in the $\mathrm{UK}$ is the numerical dominance of businesses which have no employees (owner-only), 69.5\%. Furthermore, just over two thirds (67.3 per cent) describe themselves as family-owned. About a fifth (20.8 per cent) are exporters, conducting at least some of their business outside the UK. Service sector account for the bulk of the total, at 71.8 per cent, and these include businesses in retailing, hotels and restaurants, transport and communications, financial services, business services, education, health and social work, and other services [73].

Small businesses have been suggested to tend to be more risky than larger companies $[8,76,18]$ being subject to higher firm failure rates $[40,15]$. They have been also found to keep less adequate records $[63,47]$. Storey and Cressy [68] also characterise SMEs as having little control over their environment and having small market shares. Therefore, they are unable to erect barriers to entry to their industry and tend to be heavily dependent on a small number of customers.

Most SMEs have been found to lack technical expertise [3] and adequate capital to undertake technical enhancements $[29,61]$. They also suffer from inadequate organisational planning $[71,50]$. Khan and Khan [38] and Chen [14] suggested that most SMEs avoided sophisticated software or applications. They have been found 
to use ICT as tools to support specific organisational tasks such as administration and accounting, rely on standard, off-the-shelf solutions, and on external support [20].

Initially, the Internet was regarded as an important opportunity for small companies, aimed at improving their relationship with the market, reaching wider geographical markets and increasing customers [59]. The Internet's ability to reach new markets or customers and enhancing sales was seen as the most important expected benefit to be gained from adopting ecommerce in companies, as reported by $36 \%$ of all the companies interviewed by KPMG [41]. However, Poon and Swatman [56] reported, in their longitudinal research about expected Internet benefits, that $45 \%$ of the Australian small firms studied were disappointed with the performance of the Internet in terms of sales and global marketing. However, those companies found benefits in using the Internet as a communication and information medium. Other benefits were found to be improved customer relationship and better business networks.

In a similar vein, recent studies found businesses now seeing the Internet primarily as a tool for cost reduction and efficiency improvement, as opposed to the former aspirations of expanding markets and increasing revenues $[7,11,23]$. For example, the CBI and KPMG [11] survey reported $87 \%$ of their respondents affirming that operational efficiency and cost reduction were key e-business drivers in their organization. In addition, improving customer service and supporting existing links with customers were found to be the next main benefits businesses had experienced or expect in the UK $[22,10,64]$. In the DTI [22] study, improving customer service and relationships were found to be the second driver for adopting Internet technologies, accounting for $16 \%$ of the responses.

It has been suggested that SMEs obtain the greatest benefits from Internet technologies when integrating different parts of the value chain (e.g. development, production, financing, marketing, sales and services, etc) transforming their business processes $[22,64]$. This integration results in internal productivity improvements (e.g. enhancing business processes, reducing production costs and inventory plus other efficiency savings). Also the benefit of full supply chain integration is cited, thereby improving businesses relations and coordination with suppliers and customers (e.g. improvements in order fulfilment, customer service and communication with suppliers) $[64,23,70]$.

SMEs have been suggested to follow an ordered sequence of stages in their adoption of Internet technologies. These staged models (also termed adoption ladders) postulate that businesses move in stages from basic use of the Internet (as an e-mail or marketing tool) to a more sophisticated use that integrates business systems and redesigns business processes $[13$, $17,60]$. It is assumed that the higher the stage that a company reaches, the greater will be the benefits obtained.

The Stages Theory has been widely used as a way of examining the adoption and progression of various aspects of e-commerce in organizations. Conceptual models depicting the stages involved in the development of Internet systems have appeared in the literature $[24,10,36,77$, $62]$. There has also been a parallel development of several models seeking to capture and describe specifically the different phases that SMEs move through with respect to the sophistication of their use of Internet technologies [22, $13,17,60]$.

Within these models, early stages of Internet adoption are typically characterized by gaining access to the Internet followed by the use of relatively simple technologies (e.g. email) to dispense and gather information. Subsequent stages relate to the establishment of a simple static home page containing basic contact information. Later the business starts to publish a wider range of information to market its products and perhaps provide after-sales support. E-commerce deployment is next, allowing the users of the site to order and/or pay for goods and services. In the most mature stages the website is fully integrated with the various back office systems such as enterprise resource planning (ERP), customer relationship management (CRM), and integrated supply chain management (SCM) applications.

In recent years, governmental programs of the UK, European Union and other governments have used one-size-fits-all staged models to encourage SME e-business adoption [22, 65, 25, $32,52,78]$. However, despite the efforts of 


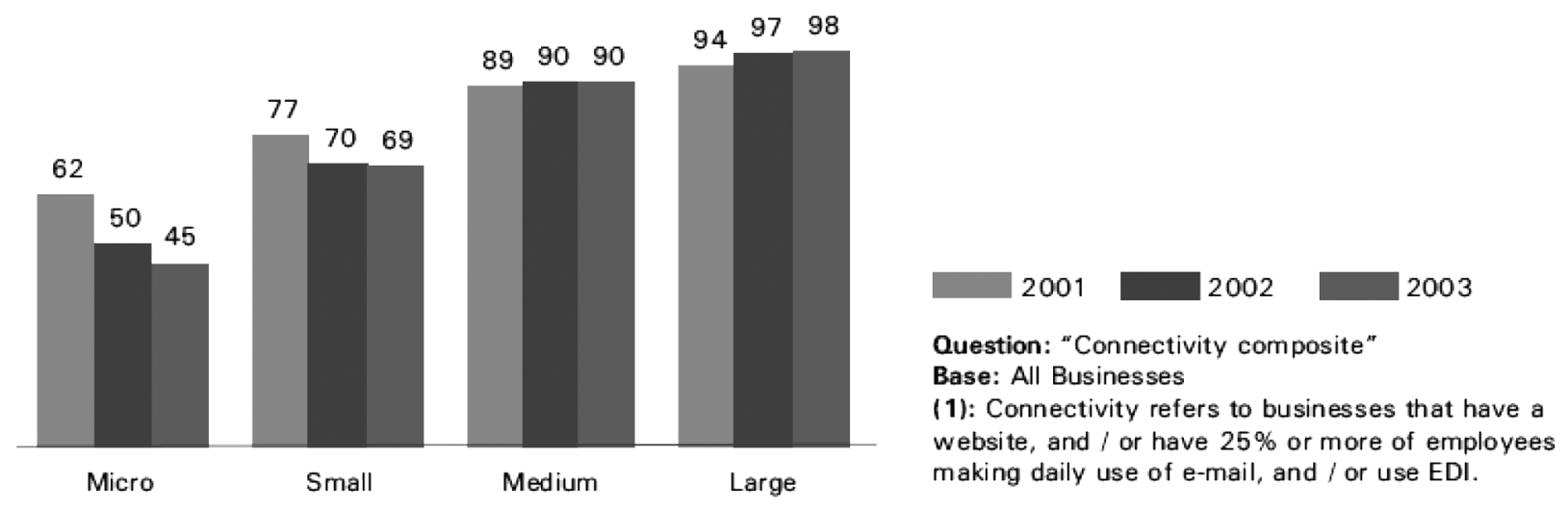

Fig. 1. Business connectivity by firm size (UK)[23].

governments and the various support programs, the achievement of the advanced stages of ecommerce by SMEs is very low and lagging behind larger companies in the use of more sophisticated ICTs $[23,26,11,27]$. Nearly a third of European large enterprises have implemented an electronic CRM system and 13\% are users of an electronic SCM system, compared with only $10 \%(\mathrm{CRM})$ and 3\% (SCM) of SMEs [27]. Furthermore, several studies of e-business in the UK report a decline in the number of SMEs implementing trading online $[7,11,27$, 23]. Perhaps surprisingly, using website and email has also declined, as Figure 1 shows [22, 23]. The DTI [22] report found a reduction in the number of micro businesses selling online of $10 \%$, while there was an increase of $7 \%$ in the case of large businesses. Therefore, perhaps these adoption models need to be questioned and possibly revised.

The aim of this paper is to examine models for describing e-business progression in SMEs. Firstly, an analysis of the Stages of Growth model looking at its weaknesses and strengths, in the context of the progression of Internet technologies adoption by SMEs in the UK, is conducted. Secondly, alternative approaches to e-business progression are presented. Next, a classification of theories of change is offered and the previous alternative models are associated with its categories. Finally, an interpretative multi-theoretical framework is proposed and its empirical validation proposed as further research.

\section{Analysis of the "Stages of Growth" Model}

This model is commonly used to illustrate and conceptualise change in biology (e.g. the growth and development of human life) as well as business (e.g. product life cycles). From this perspective, change is imminent (once an organism is conceived, or a company is founded, it grows in a particular fashion) and linear, with development typically in a unitary sequence of stages or phases, which is cumulative (development builds from previous stages) [75].

In the area of Information Systems (IS) the Stages Theory first emerged in the mid 1970s with the work of Nolan [53]. His model provided a high-level view of IS strategy and implementation suggesting that the planning, organizing, and controlling activities associated with managing the organizational computer resource change in character over a period of time, and will evolve in patterns roughly correlated to a number of stages. Each stage having its own distinctive applications, benefits and problems. Nolan's stage hypothesis has become well known in the IS literature, but also controversial $[39,4,46]$.

All of the staged models are premised on the idea that organisations progress through a number of successive, identifiable stages. Each stage reflects a particular level of maturity in terms of the use and management of IS/IT to support and facilitate business activities, processes and operations. In this way staged models offer insights into how IT and organizational strategies evolve over time [46] and have become a popular element of IS planning approaches. 
The Stages Theory still has a strong influence and variations of the early models are widely used to describe technological and organizational trajectories for a range of technological implementations. For example: Knowledge Management [30], Intranet [16], End User Computing [34], E-Government [43] and Enterprise Resource Planning Systems [31].

This theory has been widely used as a way of examining the adoption and progression of various aspects of e-commerce in organisations. Conceptual models depicting the stages involved in the development of Internet systems have appeared in the literature $[24,10,36,77,62]$.

Recent years have seen a parallel development of several staged models, seeking to capture and describe the different phases that SMEs move through, with respect to the sophistication of their use of Internet technologies [22, 13, 17, $60]$. For example, recently the DTI has used an e-adoption ladder (Figure 2) to represent the adoption of ICT by SMEs as an ongoing journey from basic access through to more sophisticated use.

The DTI e-adoption ladder views firms as starting with the basic use of e-mail for communicating; progressing towards the creation of websites; developing into the buying and selling of goods online; integrating most if not all internal processes; and, maturing into the transformation of the organisation and the construction of entirely new business models. There is some flexibility for organizational differences, since it is noted that not all firms need to pass through all the stages in sequence. Businesses may not begin the adoption process at stage one and may miss out some stages entirely, depending on their individual needs and priorities [22].

\subsection{Criticisms or Weaknesses of the "Stages of Growth" Model}

Although this model is a popular approach to explain the evolution and progression of Internet technologies adoption by organizations it has been heavily criticized. Firstly, staged models have been criticized for adopting an oversimplified perspective of complex issues and circumstances around small firm economic activity [35], making use of some very simplistic versions of organization change and innovation theory [46]. The use of simplified linear approaches to analyse innovation fails to illustrate the complex processes that may take place at macro and micro-economic level within individual small firms [28b].

Secondly, the model assumes that firms progress from basic to more advanced use of ICTs in a linear fashion. However, recent studies reported the stalling and even decline of small businesses trading online and even a decline in the use of website and e-mail in the UK [7, 22, 23, 11, 27, 74]. These two cases (reverse in e-trading and 'clicking off') suggest that e-business strategies

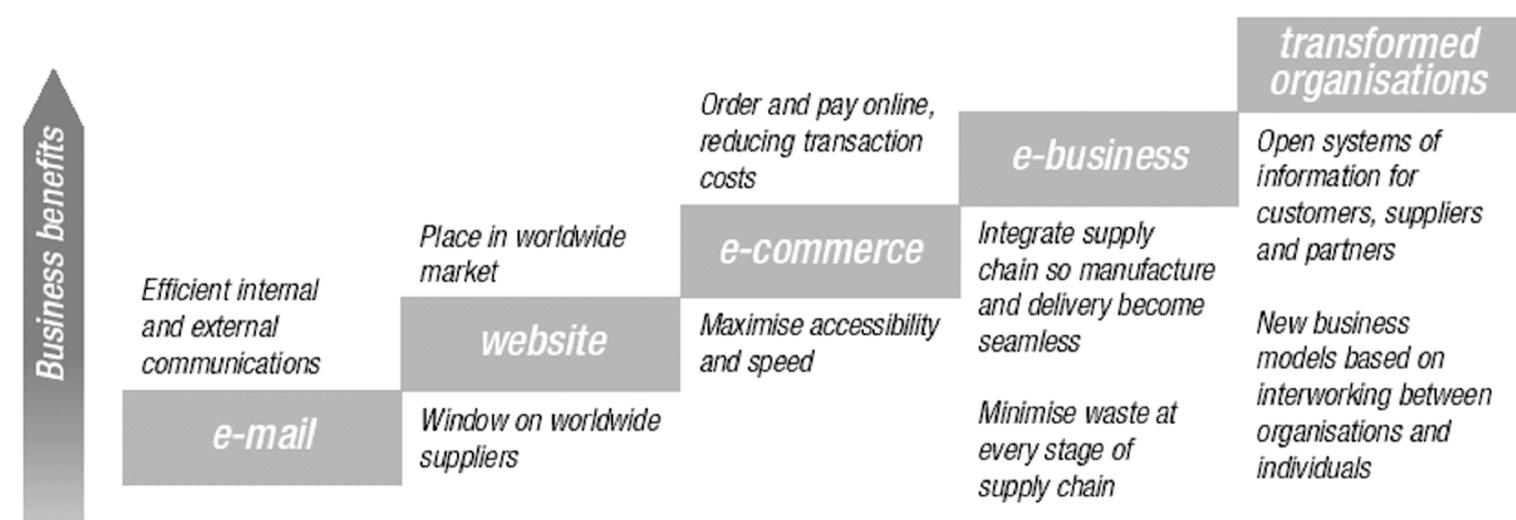

Extent of organisational change and sophistication

Fig. 2. Model of e-adoption ladder [22]. 
(rather than being an unidirectional path from a lower, simpler state to a higher, more complex one) is not borne out in practice and that actually a regressive path may occur.

Thirdly, the model has not been empirically tested. It has been widely suggested that longitudinal studies examining the same companies sequentially over time is a better approach to analyse the validity of the evolutionary path that e-business progression in these companies may follow [58, 70, 17, 44]. In fact, Rusten and Cornford [64] in their 3-year longitudinal study on the evolution of Internet strategies in firms in the UK and Norway identified a whole range of variation in the way websites developed, including the regressive cases.

A further criticism that some authors have noted is that these models are too general and suggest the same path of development for all kind of companies, not taking into account the diversity of SMEs $[45,48]$. The small business sector is not a homogeneous one but characterized by its intrinsic diversity (in size, economic activity, resource availability, etc.) and, therefore, one would expect a great deal of variations in the need for ICT and the adoption of different e-commerce strategies $[64,45,21]$.

In addition, other change theories have been suggested of providing better insights into the actual mechanisms whereby change in the use of technologies by organizations takes place [39, 42]. For example, 'evolutionary' models that describe evolution in terms of the mechanisms of change, rather than the direction of change or the likely end state, might be more appropriate. Conducting research with a single preconceived change theory in mind has the risk of oversimplification and obtaining only a partial account of the development and change process at the expense of others [75]

Finally, staged models have been accused of being concerned with the broad picture of change in the use of technologies by businesses, rather than with the actual experiences of change in individual instances [42]. Therefore, an understanding of the historical evolution of the advancements in the functionality of commercial Internet applications and the growth of industrywide experience with online business activities itself may well explain the evolutionary stages described in most of the general staged models.

\subsection{Benefits or Strengths of the "Stages of Growth" Model}

Despite these criticisms, the model is a popular framework and IS researchers have continued to use it to characterize developmental changes in organizational experiences with Internet technologies, even though these failings may acknowledge. As a recent example of their continuing use, Chan and Swatman [12] propose a staged model for B2B e-commerce implementation in Australian organizations.

The model continues to be intuitively very appealing, largely because aspects of the model ring true to both practitioners and researchers [39]. It conforms to the concept of stages in a person's learning and understanding of something new and suits our desire for orderliness and classification. Therefore, a linear model may seem attractive as a simplified way to describe ICTs adoption and use [48]. A survey on SMEs in Australia, looking at the pragmatic value of the stages concept to map the progression of e-business maturity, concludes that the stages concept is useful in a pragmatic sense in that it appeals to managers [58].

In addition, the model has proved to be a useful tool for a SME that wishes to classify itself for comparison purposes with its major competitors involved in e-commerce within its own industry or sector, and hence, indicating gaps and leading to strategic actions $[60,2]$.

A further strength is that they can provide a roadmap to assist companies to determine whether or not is sensible to progress to a subsequent stage [60]. The stages approach is useful in explaining the past, current and future involvement in e-business. One of its major strengths is the sense of guidance and direction as to where to proceed further, as well as where an organization might focus its goals and resources [58].

Finally, using the stages approach, an organisation might reduce the complexity of their ebusiness initiatives, breaking them into smaller, more flexible and manageable portions. By doing so, an organisation is able to focus more on the task at hand, constantly evaluating and assessing the progression of their e-business initiatives. A staged model can assist in identifying phases of development required and provide 
milestones that can be understood by management. Staged development may also help control costs and allow for alteration during the development process [58].

\section{Alternative Approaches}

\section{1. "Stages of Organizational Learning" Model}

It has been suggested that the stages of adoption should be replaced with stages of organizational learning $(\mathrm{OL})$ as it has been acknowledged that the commitment of owners/managers and their perception of the benefits of Internet technologies appear to be critical factors for adoption in SMEs [48].

Nolan's revised version of his staged model [54] proposes that it is organizational learning that grows in stages (instead of the computer budget). In this way, the introduction and assimilation of new technologies in organizations requires experimentation and the emergence of the four stages of organizational learning (initiation, contagion, control, and integration), which form an S-shaped curve. Nolan used his revised staged model to describe three eras characterized by the use of different technologies: the DP era (mainframes), micro-era (PCs) and network era (the Internet).
The curves of the eras overlap during periods of technological discontinuity when further development of the proven old dominant technology design clashes with the progress of the emerging and unproven new technology design. Nolan acknowledges that an organization can be in several stages for different technologies at any point of time. This stage of stages model implies the idea of ongoing evolution and growth in organizational learning in relation to IT, instead of the previous final end stage of integration [42].

Alonso Mendo and Fitzgerald [1] proposed a variation of the Nolan's revised model (Figure 3 ) where the three original eras are replaced by four eras characterized by the use of different Internet technologies: the Email era (efficient internal and external communications), Website era (place in worldwide market), e-Commerce era (order and pay online, reducing transaction costs) and e-Business era (integration of supply chain to enable seamless manufacture and delivery).

This revised model does not assume linearity as it contemplates the possibility of a company being in several stages for different technologies at any point of time. In addition, reverse steps in the adoption of e-business are also allowed and explained in the model. For example, a firm may abandon its e-commerce implementation, or even its website, in the Initiation stage, if during the experimentation the value of the technology is not proved and further investment is not justified.

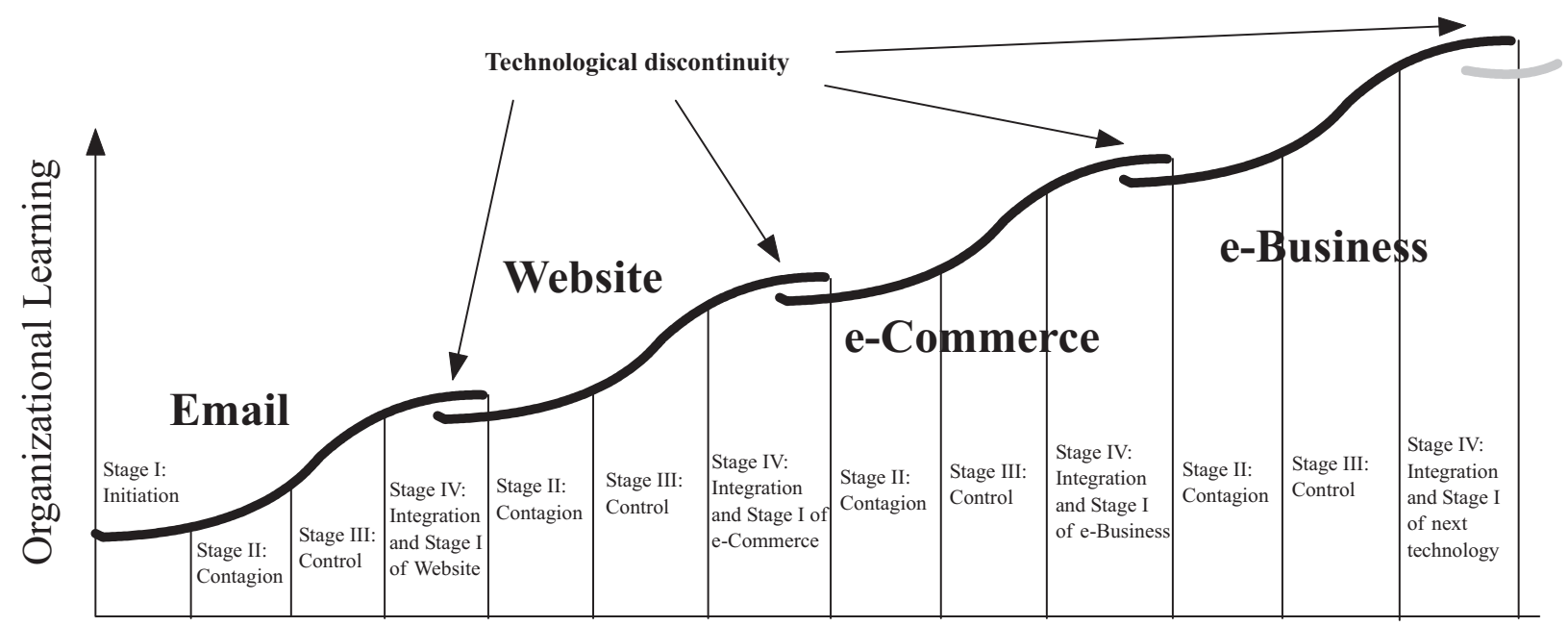

Fig. 3. E-Business Stages of OL model[1]. 


\subsection{Institutionalism Theory}

Lamb and Davidson [42], in their examination of the adoption and use of organizational intranets, criticized the Stages of Growth model and found it more useful to use the institutionalist concepts of 'isomorphic practices'. The new institutionalism in organizational theory comprises a rejection of the organizational actors' rationality and claims that the structure and behaviour of an organization are shaped by the characteristics of the environment in which it operates. In this sense, organizations within a particular industry, consciously or unconsciously, copy each other's practices over time, regardless of efficacy. Organizations are embedded in larger systems of relations ('organizational field') formed by the group of organizations providing similar products or services, their major suppliers, customers, owners, regulatory agencies, competitors, etc. $[19,57]$.

The phenomenon by which organizations are structured through their environment requirements is explained by 'isomorphic practices'. Powell and DiMaggio [57] present two types of isomorphism: competitive and institutional. Competitive isomorphism pressures occur when the forces of competition eventually push organizations toward improving efficiency. On the other hand, institutional isomorphism stresses cultural and political issues as the drivers of change. DiMaggio and Powell [19] present three mechanisms of isomorphic institutional pressures: coactive isomorphism, which is originated from political influences and legitimacy problems (e.g. legally imposed restrictions); mimetic isomorphism, which is driven by uncertainty and may result in the imitation of models of operation from successful companies and normative isomorphism, which can be associated to professions actions (e.g. codes of conduct of professional bodies).

Lamb and Davidson [42] cited three advantages of using the concept of isomorphic practices instead of the Stages Theory: (1) they help to explain repetitive practices in a non-deterministic fashion and can be viewed as 'steps' in organizational learning, which path is indeterminate. (2) These concepts explain changes in particular organizational practices as part of a larger field of dynamic industry practices and; (3) institutionalist concepts are intrinsically historical by situating actions within a realm of routines and practices that have developed over time.

\subsection{Contingent Adoption Models}

Several authors have also criticized the value of staged models to study the growth of SMEs. Storey [67] for example, suggests that the majority of firms do not progress in stages and do not necessarily have a desire or need to move or progress in this way. Instead, he suggests that progression occurs when the appropriate combination of three components takes place, namely, the characteristics of the entrepreneur(s), the characteristics of the firm and their strategy or managerial actions.

In a similar vein, Southern and Tilley [66] conclude that the small firm use of ICT cannot be formulated as a simple linear development with an incremental build up of knowledge and expertise. Instead, there are both exogenous and endogenous factors influencing the adoption, implementation and the successful management of ICT.

Brown and Lockett [9] classify the studies of ICT adoption in SMEs in three overlapping stands.

Strategic: with an emphasis on the strategic logic of the decision to adopt, depending on the degree of proactivity. For example, Martin and Matlay [48] affirm that it is the reactive or proactive approach of owner to rapid technological changes in the marketplace that is crucial to ICT adoption and implementation.

Technological: a focus on adoption as an outcome of a complex process of evaluation by SMEs of multiple factors, both external and internal, which can be either enablers or barriers to successful adoption. Mehrtens et al [49], for example, identify perceived benefits, organizational readiness, and external pressures, as the main factors that influence adoption decisions.

Organizational: a focus on the owner/manager and the social parameters within which the firm operates.

\subsection{Contingent Role Models}

A number of authors have developed contingent role models as alternatives to staged mod- 
els of Internet adoption. The idea behind these models is that different types of business will view Internet adoption in different lights. Business processes are the activities in which businesses engage as they conduct commerce. Ecommerce can be approached in many different ways, depending on the specific business process that might be carried out through the Internet [69]. Thus, several Internet usage profiles or approaches are possible. A company must determine which profile or combination of profiles best suits its particular business context and strategy. Tagliavini et al. [69] identified five e-commerce approaches, namely, public relations, company promotion, pre/post sales support, order processing and payment management. In a similar vein, Boisvert and Begin [6] suggest five Internet user profiles or roles: promoter, developer, vendor, integrator and PR officer.

Levy and Powell [45] identify four roles for Internet technologies in SMEs: brochureware, support, opportunity and development. Their model implies 'transportation' from one use to another without the implicit idea of growth included in the staged models. They suggest that different businesses will focus on different roles, depending on the owner's attitude to growth and perceived Internet value.

An illustrative example of a shift from staged models to role models can be found in the policy change of the Australian NOEI, which in the past used one such staged model to describe the path of progression by SMEs towards adopting e-commerce [52]. However, now they present five modes of e-business (participating, supporting, expanding, assimilating and transformed) [51] and acknowledge that it would be wrong to suggest that a firm that is in one mode must proceed to another mode, otherwise they will miss out on opportunities. They advise firms to consider which mode of e-business is right for their businesses and to assess if moving to another mode would be best for them or not. Factors that would determine which mode of e-business is appropriate include: types of products or services, customers and suppliers' expectations and requirements, the industry sector, size, business goals, age, etc.

\section{Theories of Change}

In trying to explain organizational change processes, six generic categories of theories have been proposed in the literature. Each theory relies on a different 'motor of change' or 'generative mechanism', which can be drawn as a distinct sequence of events $[75,37]$ namely:

Life-cycle theory (evolutionist or developmental): assumes that change is inherent and imminent. The process of change is in a linear and determined fashion. The process is cumulative, successive stages building from the previous one. The process is irreversible and there is a definitive ending point.

Teleological theory (rational): assumes that organizations are purposeful and adaptive. In other words, there is a stated goal and organizations purposefully take action to reach it. Change is rational and occurs because organizations see the necessity of change.

Dialectical theory (political): assumes that within companies there are colliding forces that compete with each other for domination and control. Change results from clashing ideology or belief systems (conflicts). Change may be triggered by a political crisis, a change in leadership, new ideas introduced in the firm, persuasion, different interest groups within the company, etc.

Evolutionary theory (natural selection): assumes that change is achieved through a selection process where the environment selects the organizations that best fit their context. There is not a predetermined end point, like in the life cycle, rather it is an on-going cycle of variation and selection. Change is seen as a reaction to external demands, institutional variables, and the particular environment faced by the firm.

Social cognition theory: explains change as tied to learning and mental processes such as sense making and mental models. Managers see a need to grow, learn and change.

Cultural theory: change happens as a response to alterations in the human environment. It can involve alteration of values, beliefs, myths and rituals in an organization.

In the light of this classification of change theories, it is possible to look at the approaches presented earlier and observe their underlying 
change theory. Firstly, the traditional staged models applied to e-business progression could be included in the life-cycle theory as they map a sequence of stages from a lower, simpler state to a higher, more complex one. However, we have seen before that this is one possible path but not the only one. E-commerce progression can also follow a regressive path, as in the case of 'reverse in e-trading' and 'clicking off'. Secondly, the revised Stages of OL model could be incorporated in both the life-cycle theory and the social cognition theory when used to explain change as a sequence of learning stages firms may go through when learning and experimenting with new technologies. Thirdly, the institutional theory applied to EC progression could be seen as incorporating both evolutionary and dialectical theories, because it explains progression as an adaptation to fit the environment in which the firm operates, including the influence of competition, cultural and political issues. Finally, contingency models assume a teleological driver, as they presume the firm adoption is rational according to a stated goal and change is seen in terms of better accomplishing the organisation objectives.

This multiplicity of approaches and theories shows that there is not one best way to approach change and development processes in ebusiness progression. Each basic change theory provides an essentially different viewpoint on the sequence of events and assumptions about the influences (or change drivers) for explaining the process of change. However, organizational change is more complex than any one of these basic theories imply, because it may involve a number of simultaneous change drivers interacting with each other and producing interdependent cycles of change. Van de Ven [75] suggests combining elements of the ideal models of change in order to reveal alternative pictures of the same organizational processes. Each approach therefore can shed light on different aspects of change, allowing us to understand a part of the processes taking place.

Conducting research with a single preconceived change theory in mind has the risk of oversimplification and obtaining only a partial account of the development and change process at the expense of others. The researcher may become biased and look only for indicators of that particular theory, ignoring other possible influences.
For example, working simply with the view of the life-cycle staged model to explain the progression of Internet activities in small companies may make a researcher expect a certain number of stages of development to occur. In complex processes it is too easy to find support for whatever one expects and therefore to ignore other potential explanations $[55,75]$.

\section{Proposed Interpretative Multi-theoretical Framework}

In order to obtain a more comprehensive understanding of how and why organizations evolve their e-business strategies and web sites over time, this paper suggests that the different explanations of e-business adoption and progression can be integrated into a multi-theoretical framework (Figure 4).

The evolution or development of e-business strategies can be seen as a dynamic sequence of changes over time. However, Van de Ven [75] differentiates two interpretations of change. Firstly, as a process or sequence of events over time and, secondly, as the empirically observable differences in the form, quality or state of the organization over time.

Following the first interpretation, the suggested framework looks at the processes of change from different viewpoints, combining assumptions from lifecycle, cognitive, teleological, evolutionary and dialectical theories. The Stages of OL model, the institutional theory, the contingent adoption models and role models described above are viewed as providing alternative pictures of the same organizational process.

In addition, the framework also considers the second interpretation of change by looking at the observable differences in the web site of an organisation over time using a web site metrics model. Such a model intends to measure the development of a web site looking at the presence of a number of components related to a potential function accomplished by the website. For example, a relational site can help reduce costs of after sales service and communication with customers and other stakeholders by implementing components such as discussion group, FAQ sections, career information, etc [5]. 
PROCESS OF CHANGE

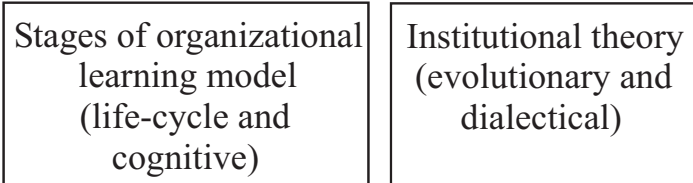

Contingent adoption model (evolutionary)
Contingent role model (teleological)

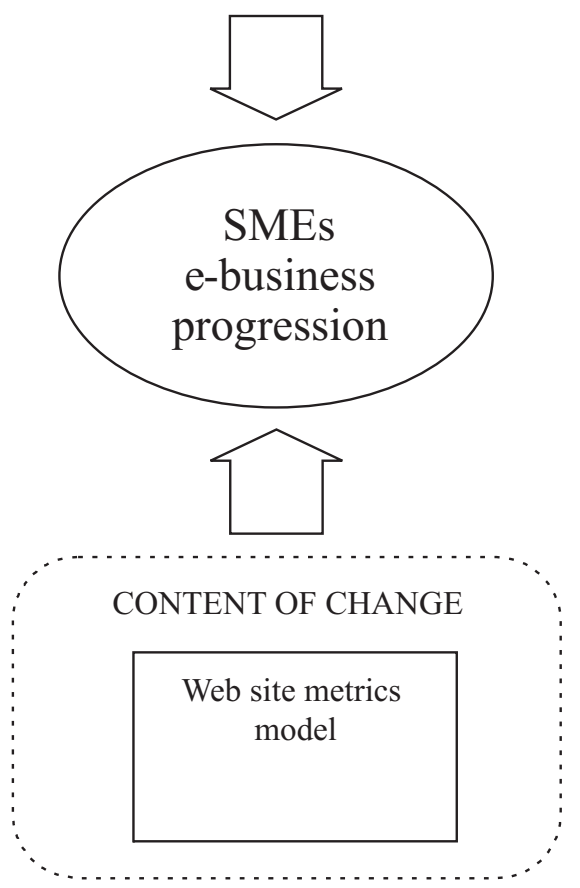

Fig. 4. Multitheoretical framework.

\section{Conclusions and Further Research}

The Stages of Growth model is one of the most common approaches to explain the evolution and progression of Internet technologies adoption by organizations. However, this approach is not exempt from criticism and other alternatives, based in different change theories, have been found in the literature. The paper examines these criticisms and alternative models and approaches. It proposes a multi-theoretical framework to overcome the problems caused by the use of one single explanation theory (e.g. staged models) in the study of the evolution of the use of Internet technologies by SMEs.

According to the Oxford and Merriam-Webster dictionaries, a model is a simple representation of reality that emphasizes some features, while ignoring others. They are used to simulate a process, understand a situation, predict an outcome, explain how something works or analyse a problem. In contrast, a framework is defined as a set of beliefs, ideas, rules, conditions or assumptions that determine how a particular type of thing or situation will be approached, perceived, or understood and can be used as the basis for making judgments and decisions. A framework is based on concepts, models, and theories and serves as a valuable tool for understanding [33]. In this vein, the proposed framework may be used by academics as a new lens to enable them to study the SMEs adoption and progression of e-business in an insightful way, avoiding the myopia of conducting research with a simple a priori theory in mind. This study will help to understand why and how SMEs evolve their websites and Internet strategies for supporting better their web maintenance and e-business strategies.

Further research is necessary to verify the validity of the suggested framework applied to SMEs e-business progression. Longitudinal case studies and/or surveys at multiple points in time 
have been suggested to examine the e-business progression within SMEs [58, 70, 17, 44]. However, little research has focused on this issue because of the long time periods needed to undertake such studies.

In the present research project a sample of UK SMEs commercial websites is being monitored during six months to detect re-developments. The changes are being analysed using the proposed framework by looking first at the content of the change. This comprises analysing the differences in the re-developed sites using a number of web evaluation metrics. Later case studies will be undertaken to explore the process of the change, which includes looking at the qualitative elements from the different models that complete the framework (stages of OL, isomorphic practices, barriers and drivers, and EC approaches).

\section{Acknowledgement}

We would like to thank Yogesh Desphande, Michael Lang and Sandra Bavarosso for their helpful comments and advice.

\section{References}

[1] F. Alonso Mendo And G. FitzGerald, An analysis of stages of growth models in SMEs e-business progression, presented at the Proceedings of the 1st European and Mediterranean Conference on Information Systems, (2004) Tunis, Tunisia.

[2] G. Azzone, R. Bianchi And G. Noci, Corporate websites: the drivers of their different configurations, Electronic Markets, 11(2) (2001), pp. 126-139.

[3] H. BARRY AND B. Milner, SMEs and Electronic Commerce: A Departure from the Traditional Prioritisation of Training?, Journal of European Industrial Training, 25(7) (2002), pp. 316-326.

[4] I. Benbasat, A. S. DeXter, D. H. Drury AND R. C. GolDSTEIN, A Critique of Stage Hypothesis: Theory and Empirical Evidence, Communications of the ACM, 27(5) (1984), pp. 476-485.

[5] H. BOISVERT, Smart web development: how Canadian companies are building online presence. CMA Management (Canada), November (2002), pp. 1822.

[6] H. BoIsvert AND L. BEGIN, Deployment of eCommerce: meeting the needs of the cyberconsumer, CMA Management (Canada), April (2002), pp. 26-29.
[7] Booz AlLEN HAMILTON, International e-Economy Benchmarking: The World's most effective policies for the e-Economy (2002), pp. London, IAP.

[8] E. F. BRIGHAM AND K. V. SMITH, The Cost of Capital to the Small Firm, The Engineering Economist, 13(1) (1967), pp. 1-26.

[9] D. H. BRown AND N. LOCKETT, Potential of critical e-applications for engaging SMEs in e-business: a provider perspective, European Journal of Information Systems, 13(1) (2004), pp. 21-34.

[10] CBI and KPMG Consulting. The quiet revolution - A report on the state of e-business in the UK, (2001).

[11] CBI and KPMG Consulting. Reality bites - The second annual report on e-business in the UK (2002).

[12] C. Chan And P. M. C. Swatman, B2B E-Commerce stages of growth: the strategic imperatives, presented at the Proceedings of the 37th Hawaii International Conference on Systems Sciences, (2004).

[13] I. Chaston, B. Badger, T. Mangles And E. SADLER-SMITH, The Internet and e-commerce: An opportunity to examine organisational learning in progress in small manufacturing firms? International Small Business Journal, 19(2) (2001), pp. 13-30.

[14] J. CHEN, The impact of microcomputers on small businesses: England 10 years later. Journal of Small Business Management, 31(3) (1993), pp. 96-102.

[15] A. Cochran, Small business mortality rates. A review of the literature, Journal of Small Business Management. 19(4) (1981), pp. 50-59.

[16] J. DAMSGAARD AND R. SCHEEPERS, Managing the crises in intranet implementation: a stage model, Information Systems Journal, 10(2) (2000), pp. 131-150.

[17] E. DANIEL, H. Wilson AND A. Myers, Adoption of E-Commerce by SMEs in the UK; Towards a stage model, International Small Business Journal, 20(3) (2002), pp. 253-270.

[18] W. DELONE, Determinants for success for computer usage in small Business, MIS Quarterly, 12(1) (1988), pp. 51-61.

[19] P. J. Dimaggio And W. W. Powell, The Iron Cage Revisited: Institutional Isomorphism and Collective Rationality in Organizational Fields, American Sociological Review, 48(4) (1983), pp. 147-160.

[20] T. DiXON, B. ThOMPSON AND P. MCALlister, The Value of ICT for SMEs in the UK: A Critical Literature Review, Report for Small Business Service Research Programme (2002). (http://www.sbs.gov.uk/content/research/)

[21] S. DREW, Strategic uses of E-Commerce by SMEs in the East of England. European Management Journal, 21(1) (2003), pp. 79-88. 
[22] DTI. Business in the Information Age - International Benchmarking Study (2002), London.

[23] DTI. Business in the Information Age - International Benchmarking Study (2003), London.

[24] M.J. EARL, Evolving the E-Business, Business Strategy Review, 11(2) (2000), pp. 33-38.

[25] eCATT and Empirica. Benchmarking progress on new ways of working and new forms of business across Europe - ECaTT final report ( 2000). (http://www.ecatt.com)

[26] eEUROPE Go Digital. Benchmarking National and Regional E-business Policies for SMEs - Final Report of the E-business Policy Group, European Commission (2002).

[27] EU. Adapting e-business policies in a changing environment: The lessons of the Go Digital initiative and the challenges ahead. $\operatorname{COM}(2003) 148$ final of 27 March (2003).

[28] EU Commission. Commission Recommendation of 6 May 2003 concerning the definition of small and medium-sized enterprises. Official Journal Of European Journal (L 124/36).

[29] M. FALLON AND P. MORAN, Information Communication Technology (ICT) and Manufacturing SMEs, paper presented at The 2000 Small Business and Enterprise Development Conference, 10-11 April (2000), Manchester University, Manchester.

[30] L. R. GASKILl, H. E. VAN AUKEN AND H. KIM, The Impact of Operational Planning on Small Business Retail Performance, Journal of Small Business Strategy. 5(1) (1993), pp. 21-35.

[31] P. GotTschalk, Toward a model of growth stages for knowledge management technology in law firms, Informing Science, 5(2) (2002), pp. 79-93.

[32] C. Holland, And B. Light, A stage Maturity Model for Enterprise Resource Planning Systems Use, The Database for Advances in Information Systems, 32 (2) (2001), pp. 34-45.

[33] Industry Canada. Beyond the Web Site, An Ecommerce survival guide for Canadian firms. (1999) (http: //www.itac.ca/client/ITAC/ITAC_UW_ MainEngine.nsf/0/f8fb66198f6ce89c85256 775006729 e6? OpenDocument)

[34] N. JAYARATNA, Understanding and evaluating methodologies - NIMSAD: a systemic framework, McGraw-Hill (1994), London.

[35] R. JAYASURIYA, Stages of growth in end-user computing: applications in the health sector of developing countries in Asia-Pacific, Journal of Information Technology, 8 (1993), pp. 151-159.

[36] J. KAI-UWE BROCK, Information and technology in the small firm, in Carter, S. and Jones-Evans, D. (Eds.), Enterprise and the Small Business, Financial Times, Prentice Hall, Pearson Education, (2000), pp. 384-408.
[37] D. R. Kalakota And M. Robinson, E-Business: Roadmap for success, (1999), Massachusetts, Addison-Wesley.

[38] A. KEZAR, Understanding and facilitating organizational change in the 21st Century: Recent research and conceptualisations, ASHE-ERIC Higher Education Reports, (2001), Washington, D.C.

[39] E. KHAN AND G. KHAN, Microcomputers and small business, Bahrain Industrial Management and Data Systems, 92(6) (1992), pp. 24-28.

[40] J. L. KING AND K. L. KRAEMER, Evolution and organizational information systems: an assessment of Nolan's stage model, Communications of the ACM, 27(5) (1984), pp. 466-475.

[41] L. A. KLATT, Small Business Management: Essential in Entrepreneurship, (1973), Wadsworth, CA.

[42] KPMG Consulting. Electronic Commerce Research Report (1999), (http://web.archive.org/web /20030323164734/www. kpmgconsulting.co. uk/research/othermedia/eint3_ecomm.pdf)

[43] R. LAMB AND E. DAVIDSON, Understanding Intranets in the Context of End-User Computing, Data Base, 35(4) (2004).

[44] K. LAYNE AND J. LEE, Developing fully functional E-government: A four stage model, Government Information Quarterly 18 (2001), pp. 122-136.

[45] N. M. LEVEnburG, T. V. SChWARZ AND T. C. DANDRIDGE, Understanding Adoption of Internet Technologies, Presented at The United States Association for Small Business and Entrepreneurship (USASBE) National Conference, (2002), Reno, Nevada, USA.

[46] M. LEVY AND P. PoweLL, Exploring SME Internet Adoption: towards a contingent model, Electronic Markets, 13(2) (2003), pp. 173-181.

[47] K. LYYTINEN, Penetration of information technology in organizations, Scandinavian Journal of Information Systems, 3 (1991), pp. 87-109.

[48] R.E. Markland, The Role of the Computer in Small Business Management, Journal of Small Business Management, 12(1) (1974), pp. 21-26.

[49] L. M. MARTIN AND H. MATLAY, 'Blanket' approaches to promoting ICT in small firms: some lessons from the DTI ladder adoption model in the UK, Internet Research: Electronic Networking Applications and Policy, 11(5) (2001), pp. 399-410.

[50] J. Mehrtens, P. B. Cragg And A. M. Mills, A Model of Internet Adoption by SMEs, Information and Management, 39 (2001), pp. 165-176.

[51] N. L. Miller AND T.L. Besser, The Importance of Community Values in Small Business Strategy Formation: Evidence from Rural Iowa, Journal of Small Business Management, 38(1) (2000), pp. 68-85. 
[52] NOEI (National Office of the Information Economy). e-businessguide: an Australian guide to doing business online (2003), Commonwealth of Australia, (http://www.ebusinessguide.gov .au/site/text_only.cfm? nav_id=549)

[53] NOEI (National Office of the Information Economy). Taking the Plunge 2000 - Sink or Swim? (2000), Commonwealth of Australia.

[54] R. Nolan, Managing the computer resource: a stage hypothesis, Communications of the ACM, 16 (7) (1973), pp. 399-405.

[55] R. NOLAN, Information Technology Management Since 1960. In A Nation Transformed by Information: How Information Has Shaped the United States from Colonial Times to the Present. (Eds. A. Chandler Jr. and J. Cortada), (2000), pp. 217-256, Oxford University Press, New York.

[56] M. S. Poole, Decision development in small groups I: A test of two models. Communication Monograph., 48 (1981), pp. 1-24.

[57] S. PoOn AND P. A. SwATMAN, longitudinal study of expectations in small business internet commerce. International Journal of Electronic Commerce, 3(3) (1999), pp. 21-33.

[58] W. W. Powell AND P. J. Dimaggio, (Eds.). The new institutionalism in organizational analysis, (1991), University of Chicago Press, Chicago.

[59] A. Prananto, P. Marshall and J. MCKay, Stages of growth for e-business: an analysis of the perceived usability of the stages of growth model in ebusiness progression. Presented at the Proceedings of the 4th International Conference on Electronic Commerce (ICEC'02) (2002), Hong Kong.

[60] J. A. QUELCH AND L. R. KLEIN, The Internet and International Marketing, Sloan Management Review, 37(3) (1996), pp. 60-75.

[61] S. S. Rao, G. Metts and C. A. Mora Monge, Electronic commerce development in small and medium sized enterprises; a stage model and its implications, Business Process Management, 9(1) (2003), pp. 11-32.

[62] L. RAYMOND, Determinants of Web Site Implementation in Small Business. Internet Research: Electronic Network Applications and Policy. 11(5) (2001), pp. 411-422.

[63] J. F. RAYPORT AND B. J. JAWORSKI, Introduction to E-Commerce, (2002), Boston, McGraw Hill.

[64] W. Roтch, Management of Small Enterprises: Cases and Reading. University of Virginia Press (1967).

[65] G. Rusten AND J. CORNFORD, Web-site strategies and performance in SMEs: performance indicators and regional challenges. Paper presented at the Regional Studies Association International Conference (2003), Pisa, Italy.
[66] SIBIS and European Communities. Benchmarking E-commerce in the Information Society in Europe and the US (2003), Milan, Databank Consulting.

[67] A. Southern AND F. TILlEy, Small firms and information and communication technologies (ICTs): Toward a typology of ICTs usage. New Technology, Work, and Employment, 15 (2) (2000), pp. $138-154$.

[68] D. STOREY, Understanding the Small Business Sector, (1994), London, Routledge.

[69] D. Storey And R. CRessy, Small Business Risk: A Firm and Bank Perspective. Working Paper. SME Centre (1995), Warwick Business School.

[70] M. Tagliavini, A. Ravarini And A. Antonelli, An evaluation model for Electronic Commerce activities within SMEs. Information Technology and Management, 2(2) (2001), pp. 211-230.

[71] T S. H. TEO AND Y. A. PIAN, contingency perspective on Internet adoption and competitive advantage. European Journal of Information Systems, 12 (2) (2003), pp. 78-92.

[72] E. TetTeh And J. Burn, Global Strategies for SMEbusiness: Applying the SMALL Framework. Logistics Information Management. 14(1/2) (2001), pp. 171-180.

[73] The Small Business Service - Department Of Trade and Industry. SME Statistics for the UK 2002 (2003), (http://www.sbs.gov.uk/default -php?page=/analytical/statistics/ default.php)

[74] The Small Business Service - Department Of Trade and Industry. Annual Small Business Survey 2003 (2004).

[75] UK Online. UK Online annual report (2002), London, UK.

[76] A. H. VAn De Ven And M. S. Poole, Explaining development and change in organizations. The Academy of Management Review, 20(3) (1995), pp. 510-540.

[77] E. WALKER, Investment and Capital Structure Decision Making in Small Business in Walker E. (ed.) The Dynamic Small Firm, (1975), Texas, Selected Readings Austin Press.

[78] L. Willcocks, C. SAuer And Associates. Moving to e-Business: The Ultimate Practical Guide to Effective e-Business. (2000), Random House Business Books.

[79] V. Williams AND B. D. Phillips, E-Commerce: Small Businesses Venture Online, Office of Advocacy, US Small Business Administration (1999), Washington, DC, (www.sba.gov/advo/ stats/e_comm.pdf). 
Received: July, 2004

Revised: August, 2004

Accepted: August, 2004

Contact address:

Fernando Alonso Mendo

Brunel University

Department of Information Systems and Computing

Uxbridge

Middlesex, UB8 3PH

UK

e-mail: fernando.alonso@brunel.ac.uk

Guy Fitzgerald

Brunel University
Department of Information Systems and Computing

Uxbridge

Middlesex, UB8 3PH

UK

e-mail: guy.fitzgerald@brunel.ac.uk

FERNANDO Alonso MENDO is a PhD student at the Department of Information Systems and Computing of Brunel University. His areas of interest include e-Commerce, IS Development and Website evolution.

GUY FITZGERALD is Professor of Information Systems at Brunel University. Prior to this he was the Cable and Wireless Professor of Business Information Systems at Birkbeck College, University of London. And before this he held positions at Templeton College, Oxford and Warwick Universities. He has also worked in the computer industry for many years with companies such as British Telecom, Mitsubishi and CACI, Inc. International, in a variety of roles, including those of programmer, systems analyst and consultant. His research interests are concerned with information systems and information management and he has published widely in these areas. In particular his research has been concerned with the effective development of information systems and methodologies. More recently, he has addressed the area of information systems strategy and has developed a framework for ensuring the effective linking of business and IT strategy and has undertaken an in-depth study of IT outsourcing in the UK. He is Editor of the Information Systems Journal from Blackwell Scientific and Editor of the Information Systems Series of texts from McGraw-Hill. 